University of Nebraska - Lincoln

DigitalCommons@University of Nebraska - Lincoln

Papers in the Earth and Atmospheric Sciences Earth and Atmospheric Sciences, Department

2006

\title{
Pumping-Induced Drawdown and Stream Depletion in a Leaky Aquifer System
}

James J. Butler Jr.

University of Kansas Main Campus, jbutler@kgs.ku.edu

Xiaoyong Zhan

University of Kansas Main Campus

Vitaly A. Zlotnik

University of Nebraska-Lincoln, vzlotnik1@unl.edu

Follow this and additional works at: https://digitalcommons.unl.edu/geosciencefacpub

Part of the Earth Sciences Commons

Butler, James J. Jr.; Zhan, Xiaoyong; and Zlotnik, Vitaly A., "Pumping-Induced Drawdown and Stream Depletion in a Leaky Aquifer System" (2006). Papers in the Earth and Atmospheric Sciences. 275. https://digitalcommons.unl.edu/geosciencefacpub/275

This Article is brought to you for free and open access by the Earth and Atmospheric Sciences, Department of at DigitalCommons@University of Nebraska - Lincoln. It has been accepted for inclusion in Papers in the Earth and Atmospheric Sciences by an authorized administrator of DigitalCommons@University of Nebraska - Lincoln. 


\title{
ground water \\ Pumping-Induced Drawdown and Stream Depletion in a Leaky Aquifer System
}

\author{
by James J. Butler Jr. ${ }^{1}$, Xiaoyong Zhan ${ }^{2}$, and Vitaly A. Zlotnik ${ }^{3}$
}

\begin{abstract}
The impact of ground water pumping on nearby streams is often estimated using analytic models of the interconnected stream-aquifer system. A common assumption of these models is that the pumped aquifer is underlain by an impermeable formation. A new semianalytic solution for drawdown and stream depletion has been developed that does not require this assumption. This solution shows that pumping-induced flow (leakage) through an underlying aquitard can be an important recharge mechanism in many stream-aquifer systems. The relative importance of this source of recharge increases with the distance between the pumping well and the stream. The distance at which leakage becomes the primary component of the pumping-induced recharge depends on the specific properties of the aquifer, aquitard, and streambed. Even when the aquitard is orders of magnitude less transmissive than the aquifer, leakage can be an important recharge mechanism because of the large surface area over which it occurs. Failure to consider aquitard leakage can lead to large overestimations of both the drawdown produced by pumping and the contribution of stream depletion to the pumping-induced recharge. The ramifications for water resources management and water rights adjudication can be significant. A hypothetical example helps illustrate these points and demonstrates that more attention should be given to estimating the properties of aquitards underlying stream-aquifer systems. The solution presented here should serve as a relatively simple but versatile tool for practical assessments of pumping-induced stream-aquifer interactions. However, this solution should not be used for such assessments without site-specific data that indicate pumping has induced leakage through the aquitard.
\end{abstract}

\section{Introduction}

A large body of work has shown that pumping from wells in shallow aquifers can affect flow in nearby streams in interconnected stream-aquifer systems (Theis 1941; Glover and Balmer 1954; Hantush 1965; Hunt 1999; Butler et al. 2001). The degree to which streamflow is impacted by pumping is an important consideration for applications ranging from water resources management to water rights

${ }^{1}$ Corresponding author: Kansas Geological Survey, 1930 Constant Avenue, Campus West, University of Kansas, Lawrence, KS 66047; (785) 864-2116; fax (785) 864-5317; jbutler@kgs.ku.edu

2Kansas Geological Survey, 1930 Constant Avenue, Campus West, University of Kansas, Lawrence, KS 66047; xzhan@mactec. com. Currently with MACTEC Engineering and Consulting Inc., 600 Grand Ave., Oakland, CA 94610.

${ }^{3}$ Department of Geosciences, University of Nebraska-Lincoln, Lincoln, NE 68588; vzlotnik1@unInotes.unl.edu

Received April 2005, accepted August 2006.

Copyright (C) 2006 The Author(s).

Journal compilation (@) 2006 National Ground Water Association. doi: 10.1111/j.1745-6584.2006.00272.x adjudication to ecosystem assessments. Estimates of this impact are often obtained using analytic models of the stream-aquifer system. Although such models are greatly simplified representations of reality, they can provide important insights into system behavior when the major features of the system are represented. Over the past 60 years, a number of analytic models have been developed based on different conceptualizations of the stream-aquifer system (see Zlotnik 2004 for a brief review). A common assumption of these models is that the aquifer is underlain by a unit of relatively low permeability that acts as an impermeable barrier to flow. Recently, Zlotnik (2004), following up on work of Hantush $(1955,1964)$, has questioned the universality of that assumption and shown that pumping-induced flow (leakage) through an underlying unit of low permeability (aquitard) can have a significant impact on stream depletion calculations. That work, however, focused only on stream depletion in a simplified streamaquifer system. An extension to consider both drawdown and stream depletion in more realistic configurations is clearly needed. That is the purpose of this paper. 
The primary objectives of this paper are to develop a new semianalytic solution for assessing drawdown and stream depletion in more realistic stream-aquifer systems than those previously considered and to explore the contribution of aquitard leakage to pumping-induced recharge in those systems. The paper begins with the development of a general solution for drawdown and stream depletion in a stream-leaky aquifer system based on the partially penetrating stream model of Butler et al. (2001) and the Hantush (1960) model of flow in a compressible aquitard. This solution is then used to assess the impact of pumping-induced leakage on drawdown and stream depletion. A hypothetical example motivated by recent field work of the Kansas Geological Survey (KGS) demonstrates the major points of the theoretical assessment. This example also illustrates how uncertainty in aquitard properties influences estimates of pumping impacts in interconnected stream-aquifer systems. The paper concludes with a discussion of the ramifications of aquitard leakage for management of stream-aquifer systems undergoing ground water development.

\section{Problem Statement}

This paper addresses the issue of the drawdown and stream depletion produced by pumping from a fully penetrating well in the leaky aquifer system of Figure 1. Following the approach of Butler et al. (2001), flow properties are assumed uniform within each zone of the upper aquifer, and vertical flow within that aquifer is neglected (Dupuit assumptions). The stream and upper aquifer are separated by a thin zone of relatively low hydraulic conductivity, which is represented mathematically as an incompressible layer (Hantush 1965). Portions of the upper aquifer underneath the stream are confined but can be confined or unconfined elsewhere. Flow in the aquitard is incorporated using the model of Hantush (1960), which includes aquitard storage but neglects lateral flow. Similar to Hantush $(1955,1964)$, the underlying (lower) aquifer is assumed to be a unit of relatively high permeability so that heads within that aquifer are unaffected by pumping in the upper aquifer. Note that the conceptualization considered here is markedly different from the semiconfined system of Hunt (2003). In that case, a low-permeability unit is overlying a shallow aquifer with an impermeable base. Although pumping in the shallow aquifer induces dewatering of the overlying aquitard, all recharge is ultimately provided by the stream. In the model described here, both the stream and the lower aquifer serve as sources of recharge. Further details concerning the mathematical representations used in this and related models can be found in Butler et al. (2001), Zlotnik (2004), and Zhan and Butler (2005).

\section{Governing Equations}

$$
\begin{aligned}
& \frac{\partial^{2} s_{1}}{\partial x^{2}}+\frac{\partial^{2} s_{1}}{\partial y^{2}}-\frac{k_{\mathrm{c}}}{T_{1}} \frac{\partial s_{\mathrm{c}}}{\partial z}=\frac{S_{1}}{T_{1}} \frac{\partial s_{1}}{\partial t}, \\
& \quad-x_{\mathrm{lb}} \leq x \leq-w,-\infty<y<\infty, t>0
\end{aligned}
$$

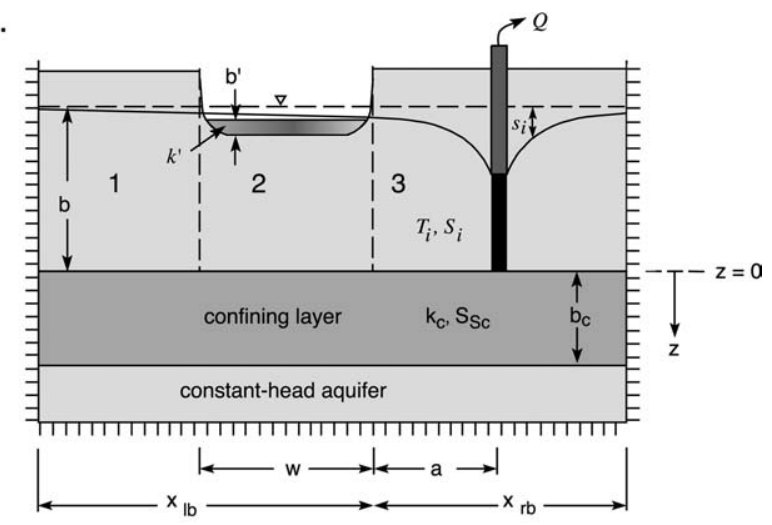

b.

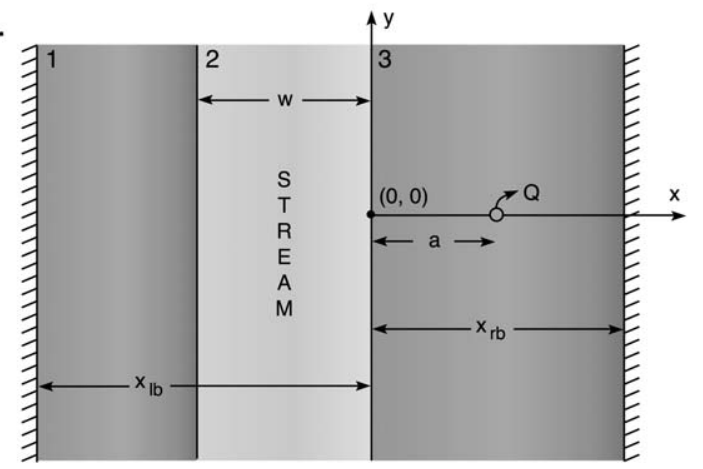

Figure 1. Schematic (a) cross-sectional and (b) areal views of the stream-aquifer system considered in this paper (notation explained in text; stream depletion in this configuration consists of vertical leakage across the low-permeability streambed; after Butler et al. [2001]).

$$
\begin{gathered}
\frac{\partial^{2} s_{2}}{\partial x^{2}}+\frac{\partial^{2} s_{2}}{\partial y^{2}}-\frac{k_{\mathrm{c}}}{T_{2}} \frac{\partial s_{\mathrm{c}}}{\partial z}-\frac{k^{\prime}}{T_{2} b^{\prime}} s_{2}=\frac{S_{2}}{T_{2}} \frac{\partial s_{2}}{\partial t} \\
-w \leq x \leq 0,-\infty<y<\infty, t>0 \\
\frac{\partial^{2} s_{3}}{\partial x^{2}}+\frac{\partial^{2} s_{3}}{\partial y^{2}}-\frac{k_{\mathrm{c}}}{T_{3}} \frac{\partial s_{\mathrm{c}}}{\partial z}+\frac{Q}{T_{3}} \delta(x-a) \delta(y)=\frac{S_{3}}{T_{3}} \frac{\partial s_{3}}{\partial t} \\
0 \leq x \leq x_{\mathrm{rb}},-\infty<y<\infty, t>0 \\
\frac{\partial^{2} s_{\mathrm{c}}}{\partial z^{2}}=\frac{S_{\mathrm{Sc}}}{k_{\mathrm{c}}} \frac{\partial s_{\mathrm{c}}}{\partial t}, 0 \leq z \leq b_{\mathrm{c}},-x_{\mathrm{lb}} \leq x \leq x_{\mathrm{rb}} \\
-\infty<y<\infty, t>0
\end{gathered}
$$

Initial Conditions

$$
\begin{aligned}
& s_{i}(x, y, 0)=0,-x_{\mathrm{lb}} \leq x \leq x_{\mathrm{rb}},-\infty<y<\infty, \\
& \quad i=1,2,3 \\
& s_{\mathrm{c}}(x, y, z, 0)=0,-x_{\mathrm{lb}} \leq x \leq x_{\mathrm{rb}},-\infty<y<\infty, \\
& 0 \leq z \leq b_{\mathrm{c}}
\end{aligned}
$$

\section{Boundary Conditions}

$$
\frac{\partial s_{1}}{\partial x}\left(-x_{\mathrm{lb}}, y, t\right)=\frac{\partial s_{3}}{\partial x}\left(x_{\mathrm{rb}}, y, t\right)=0,-\infty<y<\infty, t>0
$$


$s_{i}(x, \pm \infty, t)=0,-x_{\mathrm{lb}} \leq x \leq x_{\mathrm{rb}}, t>0, i=1,2,3$

$$
s_{1}(-w, y, t)=s_{2}(-w, y, t),-\infty<y<\infty, t>0
$$

$$
\frac{\partial s_{1}}{\partial x}(-w, y, t)=\frac{T_{2}}{T_{1}} \frac{\partial s_{2}}{\partial x}(-w, y, t),-\infty<y<\infty, t>0
$$

$$
s_{2}(0, y, t)=s_{3}(0, y, t),-\infty<y<\infty, t>0
$$$$
\frac{\partial s_{2}}{\partial x}(0, y, t)=\frac{T_{3}}{T_{2}} \frac{\partial s_{3}}{\partial x}(0, y, t),-\infty<y<\infty, t>0
$$

$$
\begin{aligned}
& s_{i}(x, y, t)=s_{\mathrm{c}}(x, y, 0, t),-x_{\mathrm{lb}} \leq x \leq x_{\mathrm{rb}}, \\
& -\infty<y<\infty, t>0
\end{aligned}
$$

$$
s_{\mathrm{c}}\left(x, y, b_{\mathrm{c}}, t\right)=0,-x_{\mathrm{lb}} \leq x \leq x_{\mathrm{rb}},-\infty<y<\infty, \quad t>0
$$

In the previous expressions, $x, y$, and $z$ are Cartesian coordinates; $i$ is zone number $(i=1,2,3) ; s_{i}(x, y, t)$ is drawdown in the upper aquifer in zone $i ; T_{i}$ is transmissivity of the upper aquifer in zone $i ; S_{i}$ is specific yield or storativity of the upper aquifer in zone $i ; k^{\prime}$ is hydraulic conductivity of streambed; $b^{\prime}$ is streambed thickness; $s_{\mathrm{c}}(x, y, z, t)$ is drawdown in the aquitard; $k_{\mathrm{c}}$ is hydraulic conductivity of aquitard; $Q$ is pumping rate from a well fully penetrating the upper aquifer and located at $x=a$, $y=0 ; x_{\mathrm{lb}}, x_{\mathrm{rb}}$ are distances from right boundary of stream to left and right lateral boundary of the aquifer, respectively; $w$ is stream width; $S_{\mathrm{Sc}}$ is specific storage of the aquitard; and $b_{\mathrm{c}}$ is aquitard thickness. A constant rate of pumping is assumed for this development, but a variable rate of pumping or a cyclic pumping pattern can be readily incorporated using standard convolution approaches (Jenkins 1968; Wallace et al. 1990).

The rate of stream depletion $(\Delta q)$ is defined as the total volumetric discharge across the incompressible streambed at any given time (Figure 1):

$$
\Delta q(t)=\frac{k^{\prime}}{b^{\prime}} \int_{-\infty}^{\infty} \int_{-w}^{0} s_{2} \mathrm{~d} x \mathrm{~d} y, t>0
$$

Equation 15 is written in terms of drawdown, not head, so, as can be shown through superposition (e.g., Bear 1979), the calculated rate of stream depletion encompasses depletion produced by direct loss from the stream channel as well as that produced by interception of flow to the stream (the case of a water table sloping toward the stream). Although Equation 15 is written for a streamaquifer system of infinite length parallel to the stream, Butler and Tsou (2003) have proven that $\Delta q$ estimates obtained using the infinite-stream formulation of Equation 15 are also applicable to finite-length stream systems truncated by impermeable boundaries (e.g., dam or bedrock high).
The mathematical model defined by Equations 1 through 15 was solved using the same approach as outlined in Butler et al. (2001). Transform space expressions for both drawdown and the rate of stream depletion are given in Appendix 1. The form of the solution is the same as that of Butler et al. (2001) except that the $\lambda_{i}$ parameter has been redefined to incorporate leakage through the underlying aquitard. Further details are provided in Zhan and Butler (2005).

This new solution reduces to existing solutions for special cases. The expressions for drawdown and the stream depletion rate reduce to those of Butler et al. (2001) when the aquitard is considered an impermeable unit $\left(k_{\mathrm{c}} \rightarrow 0\right)$, while the expression for drawdown reduces to that of Hantush (1960) for the case of a uniform aquifer $\left(T_{i}=T\right.$ and $S_{i}=S$ ) and an impermeable streambed $\left(k^{\prime} \rightarrow 0\right)$. If the incompressible aquitard conceptualization of Hantush and Jacob (1955) is adopted $\left(S_{\mathrm{Sc}} \rightarrow 0\right)$, the stream is assumed to penetrate through the entire upper aquifer and to be in direct hydraulic connection with that aquifer $\left(k^{\prime} \rightarrow \infty\right.$ or $\left.b^{\prime} \rightarrow 0\right)$, and the upper aquifer is assumed uniform, the expression for $\Delta q$ reduces to that of Hantush $(1955,1964)$.

The solution was also compared to a series of MODFLOW (Harbaugh and McDonald 1996) simulations (Table 1). Comparisons were performed for both drawdown and stream depletion. In all cases, the results of the solution and MODFLOW were in close agreement. Two example comparisons will be presented in later figures.

Given the preceding discussion, the proposed solution appears to be a reasonable representation of pumping-induced interactions in the interconnected streamleaky aquifer system of Figure 1. Therefore, for the remainder of this paper, the solution is used to assess the impact of aquitard leakage on drawdown and stream depletion. Dimensionless parameters are used to increase the generality of the presentation. The major dimensionless parameters used in this work are defined in Table 2.

\section{Impact of Aquitard Leakage}

\section{Drawdown}

Pumping in the shallow aquifer of Figure 1 will induce movement of water upward from the lower aquifer. This upward flux (leakage) can have a considerable impact on drawdown. The magnitude of that impact depends on the distance of the pumping well from the stream and the contrast between aquifer, aquitard, and streambed properties. The influence of the distance between the pumping well and the stream, and the contrast between aquifer and aquitard properties, is incorporated in the aquitard leakage parameter $\left(B_{\mathrm{dc}}\right)$. As shown in Figure 2, a range of drawdown responses can be generated by varying this parameter (if all other quantities are held constant, each increment in $B_{\mathrm{dc}}$ on Figure 2 represents an order of magnitude change in the hydraulic conductivity of the aquitard). If the pumping well is close to the stream, drawdown responses equal to those calculated assuming an impermeable base $\left(B_{\mathrm{dc}}=\infty\right)$ can be obtained with a relatively large value for the hydraulic conductivity of the aquitard. Thus, aquitard leakage should have a very limited impact when pumping wells 


\section{Table 1 \\ Grid Details for MODFLOW Model}

Size of model-252 columns (x), 249 rows (y), and 3 layers (z).

Spacing in $\mathrm{x}$ direction - from center of grid (cell with pumping well) to right boundary, spacing is as follows (all distances in meters, number of columns at a particular spacing given in parentheses): $\Delta x=1.0 \mathrm{~m}(101-$ includes cell with well), $\Delta \mathrm{x}=1.5 \mathrm{~m}(1), \Delta \mathrm{x}=2.0 \mathrm{~m}(1), \Delta \mathrm{x}=3.0 \mathrm{~m}(1), \Delta \mathrm{x}=4.5 \mathrm{~m}(1), \Delta \mathrm{x}=6.0 \mathrm{~m}(1), \Delta \mathrm{x}=9.0 \mathrm{~m}(1), \Delta \mathrm{x}=13 j \mathrm{~m}(1)$, $\Delta \mathrm{x}=20 j \mathrm{~m}(1), \Delta \mathrm{x}=30 j \mathrm{~m}(1), \Delta \mathrm{x}=45 j \mathrm{~m}(1), \Delta \mathrm{x}=60 j \mathrm{~m} \mathrm{(1),} \mathrm{and} \Delta \mathrm{x}=90 j \mathrm{~m}(1)$, where $j=10^{i}, i=0,1,2$. Same spacing from center of grid to left boundary except that three additional columns are used to refine grid in the vicinity of stream (location 1000 to $1010 \mathrm{~m}$ to the left of pumping well for results presented in Figures 2 and 4).

Spacing in y direction - from center of grid (cell with pumping well) to top boundary, spacing is as follows (all distances in meters, number of rows at a particular spacing given in parentheses): $\Delta \mathrm{y}=1.0 \mathrm{~m}$ (101-includes cell with well), $\Delta \mathrm{y}=1.5 \mathrm{~m}(1), \Delta \mathrm{y}=2.0 \mathrm{~m}(1), \Delta \mathrm{y}=3.0 \mathrm{~m}(1), \Delta \mathrm{y}=4.5 \mathrm{~m}(1), \Delta \mathrm{y}=6.0 \mathrm{~m}(1), \Delta \mathrm{y}=9.0 \mathrm{~m} \mathrm{(1),} \Delta \mathrm{y}=13 j \mathrm{~m}(1)$, $\Delta \mathrm{y}=20 j \mathrm{~m}(1), \Delta \mathrm{y}=30 j \mathrm{~m}(1), \Delta \mathrm{y}=45 \mathrm{jm}(1), \Delta \mathrm{y}=60 j \mathrm{~m} \mathrm{(1)}$, and $\Delta \mathrm{y}=90 \mathrm{j} \mathrm{m}(1)$, where $j=10^{i}, i=0,1,2$.

Same spacing from center of grid to bottom boundary.

Equal spacing in $\mathrm{z}$ direction: $\Delta \mathrm{z}=10.0 \mathrm{~m}$.

Boundary conditions-no-flow boundaries are defined on all sides of grid $(\mathrm{x}, \mathrm{y}, \mathrm{z})$. Boundaries in $\mathrm{x}$ and y directions are sufficiently far from the pumping well that they have negligible impact on the simulation results. Head kept constant in bottom layer of model.

are close to streams. However, if the pumping well is at a much larger distance from the stream (e.g., 2 orders of magnitude further away), a much smaller value (4 orders of magnitude less) for the hydraulic conductivity of the aquitard is required to replicate drawdown responses obtained assuming an impermeable base and aquitard leakage can potentially have a large impact on drawdown (Figure 2). The areal contour plots of Figure 3 demonstrate that aquitard leakage will impact both the extent and symmetry of the cone of depression. For a given set of aquifer and streambed properties, the areal extent of the cone of depression decreases and the symmetry increases with increases in the hydraulic conductivity of the aquitard. In both cases shown in Figure 3, the drawdown has stabilized (note the smaller drawdown for the case of aquitard leakage consistent with Figure 2). However, the primary mechanism producing that stabilization differs between the two cases. As discussed in the following

\begin{tabular}{|lll|}
\hline \multicolumn{3}{|c|}{ Table 2} \\
Definition of Major Dimensionless & Parameters \\
\hline Parameter & Notation & Expression \\
\hline Drawdown & $\Phi_{i}$ & $s_{i} T / Q$ \\
Stream depletion rate & $\Delta Q$ & $\Delta q / Q$ \\
Time & $\tau$ & $(T t) /\left(a^{2} S\right)$ \\
Stream leakage & $B_{\mathrm{dsa}}$ & $\left(b^{\prime} T / k^{\prime} a^{2}\right)^{1 / 2}$ \\
Aquitard leakage & $B_{\mathrm{dc}}$ & $\left(b_{\mathrm{c}} T / k_{\mathrm{c}} a^{2}\right)^{1 / 2}$ \\
Storage ratio & $S_{\mathrm{d}}$ & $\left(b_{\mathrm{c}} S_{\mathrm{Sc}}\right) / S$ \\
Coordinate-direction & $\xi$ & $x / a$ \\
perpendicular to stream & & \\
Coordinate-direction & $\eta$ & $y / a$ \\
parallel to stream & & $w / a$ \\
Width of stream & $\omega$ & $x_{\mathrm{lb}} / a$ \\
Distance to the left & $X_{\mathrm{LB}}$ & \\
aquifer boundary & & $x_{\mathrm{rb}} / a$ \\
Distance to the right & $X_{\mathrm{RB}}$ & \\
aquifer boundary & & \\
\hline ${ }^{1}$ Variations in transmissivity and storativity of upper aquifer ignored in this \\
study (i.e., $T_{i}=T$ and $\left.S_{i}=S\right)$. & & \\
\hline
\end{tabular}

section, failure to recognize that difference can lead to a misidentification of the major source of the pumpinginduced recharge. The differences in the symmetry of the cone of depression shown in Figure 3 indicate that a comparison of drawdown from an observation well located midway between the stream and the pumping well with that observed at a well a similar distance from the pumping well but in the opposite direction may provide some insight into the recharge source.

\section{Stream Depletion}

All of the analytic models currently used to assess the impact of ground water development on streamflow are based on the assumption that the shallow aquifer is

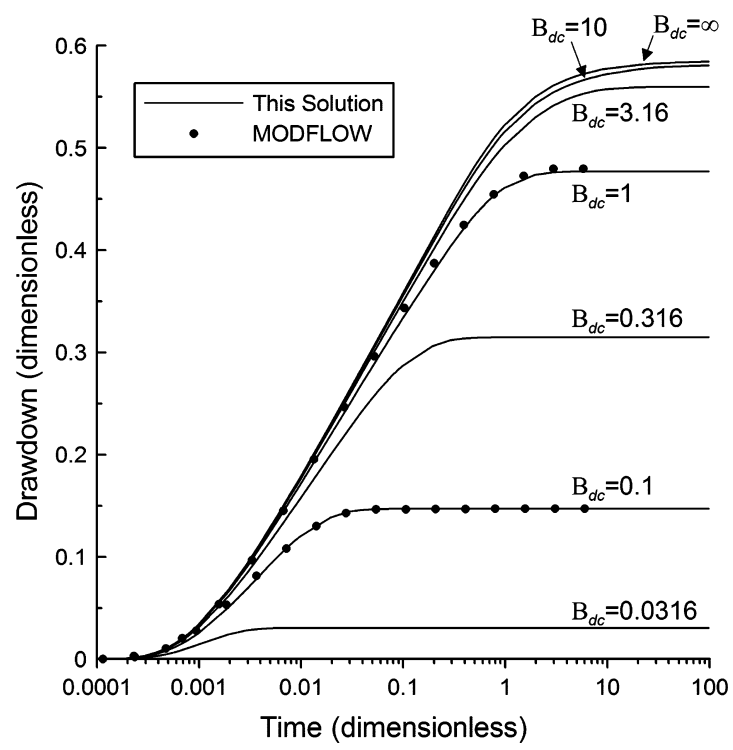

Figure 2. Dimensionless drawdown $\left(s_{3} T / Q\right)$ vs. dimensionless time $\left(T t / a^{2} S\right)$ plots as a function of the aquitard leakage parameter $\left(B_{\mathrm{dc}}=\left[T b_{\mathrm{c}} / k_{\mathrm{c}} a^{2}\right]^{1 / 2}\right.$; drawdown at $\xi=x / a=0.95$, $\eta=y / a=0 ; B_{\mathrm{dsa}}=\left[T b^{\prime} / k^{\prime} a^{2}\right]^{1 / 2}=0.01 ; \omega=w / a=0.01 ; S_{\mathrm{d}}=$ $\left(b_{\mathrm{c}} S_{\mathrm{Sc}}\right) / S=1 ; X_{\mathrm{LB}}=x_{\mathrm{lb}} / a=-\infty ; X_{\mathrm{RB}}=x_{\mathrm{rb}} / a=\infty ; B_{\mathrm{dc}}=\infty$ is for upper aquifer with an impermeable base $\left(k_{\mathrm{c}}=0\right.$, same as solution of Butler et al. [2001]); MODFLOW results generated using model grid described in Table 1). 

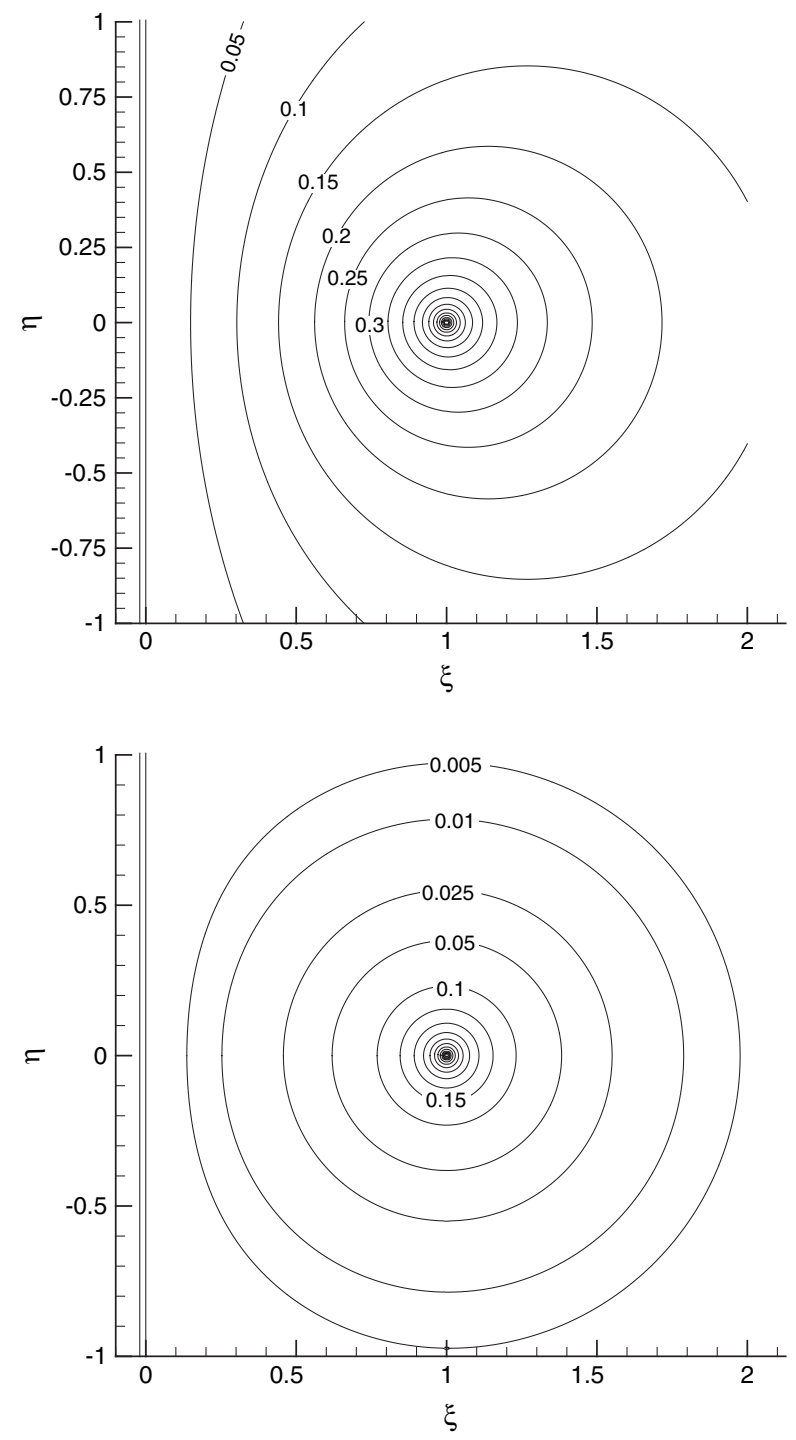

Figure 3. Contour plots of dimensionless drawdown $(\tau=10$; $B_{\mathrm{dsa}}=0.01 ; \omega=0.01 ; S_{\mathrm{d}}=1 ; X_{\mathrm{LB}}=-\infty ; X_{\mathrm{RB}}=\infty ;$ stream location marked by two parallel lines at $\xi=-0.01$ and 0 ; contour interval is 0.05 unless labeled otherwise): (a) no leakage $\left(\boldsymbol{B}_{\mathrm{dc}}=\infty\right)$ and (b) leakage through underlying aqui$\operatorname{tard}\left(B_{\mathrm{dc}}=0.316\right)$.

underlain by an impermeable unit. In that conceptualization, stream depletion must ultimately serve as the source of all of the discharged water (normalized stream depletion rate $[\Delta q / Q]$ goes to one with continued pumping). However, as shown by Zlotnik (2004) and others, the ultimate source of the discharged water may not necessarily be stream depletion when the underlying unit is an aquitard (i.e., normalized stream depletion rate may stabilize at a value less than one with continued pumping). Figure 4 illustrates how stream depletion depends on the distance of the pumping well from the stream, and the contrast in aquifer and aquitard properties. Although stream depletion is the major source of the pumpinginduced recharge when the well is in the immediate vicinity of the stream, aquitard leakage becomes an important component of that recharge for pumping wells located at greater distances from the stream. Even when the hydraulic conductivity of the aquitard is orders of magnitude less than that of the aquifer, aquitard leakage cannot be

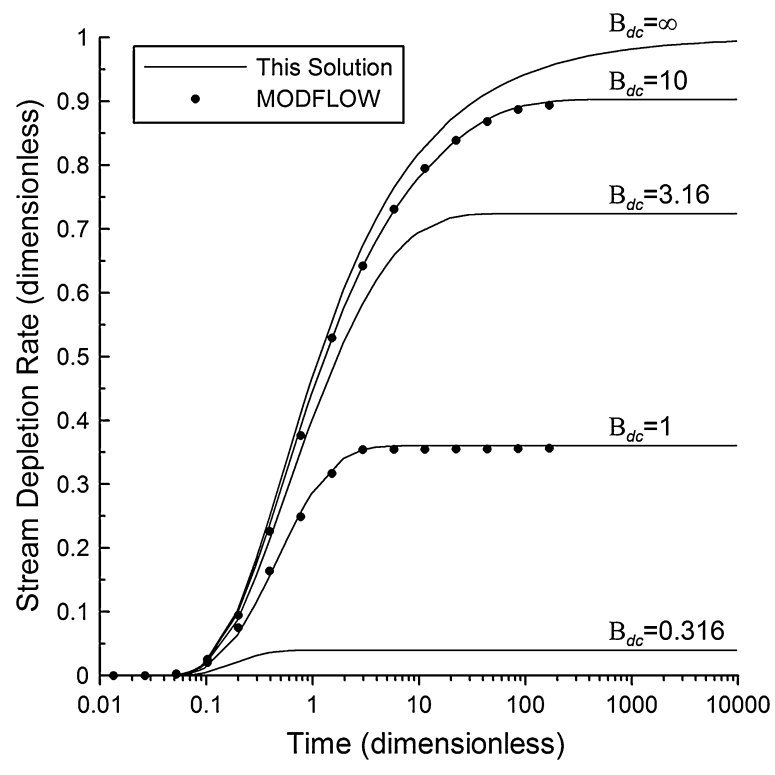

Figure 4. Normalized stream depletion rate $(\Delta q / Q)$ vs. dimensionless time plots as a function of the aquitard leakage parameter $\left(B_{\mathrm{dsa}}=0.01 ; \omega=0.01 ; S_{\mathrm{d}}=1 ; X_{\mathrm{LB}}=-\infty\right.$; $X_{\mathrm{RB}}=\infty$; MODFLOW results generated using model grid described in Table 1).

ignored because of the very large surface area through which that leakage occurs. Clearly, assessments of pumping-induced impacts on streamflow should consider the contribution of leakage through the underlying intervals of low permeability if the pumping well is not in the immediate vicinity of the stream.

The model defined by Equations 1 through 15 incorporates aquitard storage following the approach of Hantush (1960). The assumption of negligible aquitard storage (Hantush and Jacob 1955), however, is often invoked for field investigations. Figure 5 demonstrates that the ramifications of this mathematically convenient assumption are of little practical importance. Only when the storativity of the aquitard $\left(b_{\mathrm{c}} S_{\mathrm{Sc}}\right)$ is greater than that of the shallow aquifer $(S)$ will this assumption introduce significant error into the stream depletion calculations. That is a relatively rare condition because the shallow aquifer will often be unconfined and thus will have a specific yield that is considerably larger than the storativity of the aquitard.

\section{Example Application}

A hypothetical example based on field investigations of the KGS can be used to illustrate some of the practical ramifications of the preceding discussion. In the summer of 2001, the KGS established a research site along the Arkansas River near the city of Larned in south-central Kansas. The hydrostratigraphy at the site as determined by electrical conductivity profiling (Schulmeister et al. 2003) is illustrated in Figure 6. Information about the hydraulic properties of the two aquifers and the intervening aquitard was obtained from two multiday pumping tests performed by the KGS (Butler et al. 2004). This information can be used to assess the potential impact of aquitard leakage on drawdown and stream depletion in such a setting. 


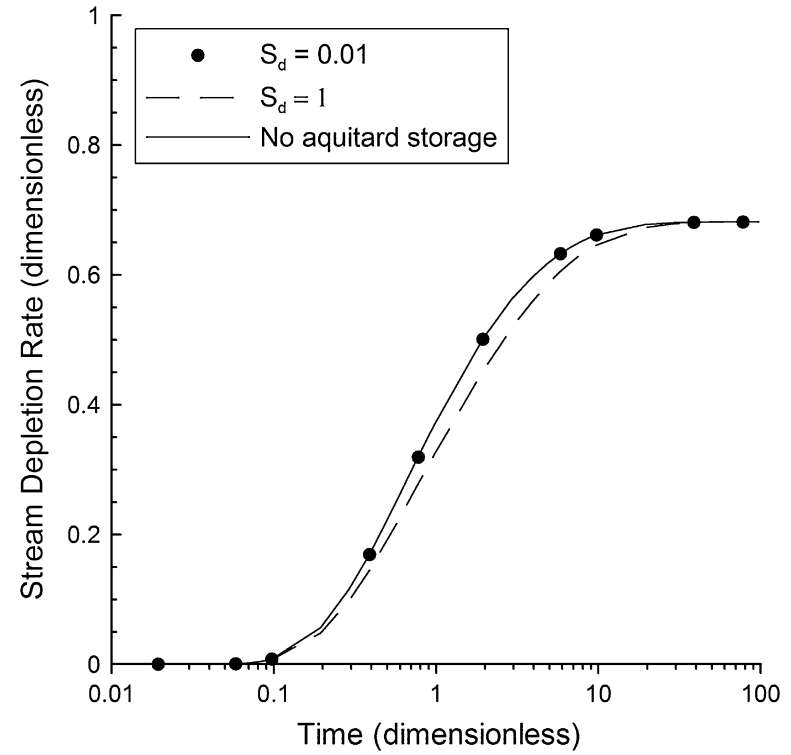

Figure 5. Normalized stream depletion rate vs. dimensionless time plots as a function of the storage parameter ratio $\left(B_{\mathrm{dc}}=3.16 ; B_{\mathrm{dsa}}=0.1 ; \omega=0.1 ; X_{\mathrm{LB}}=-\infty ; X_{\mathrm{RB}}=\infty\right)$.

Figure $7 \mathrm{a}$ presents the calculated drawdown after $7 \mathrm{~d}$ of pumping a hypothetical well in the Arkansas River alluvial aquifer located $250 \mathrm{~m}$ from the river. Parameters for the alluvial aquifer and underlying aquitard used to generate this and subsequent figures are listed in Table 3. In this case, the assumption of an impermeable base $\left(k_{\mathrm{c}}=0\right)$ appears to have little impact on the drawdown calculations as the drawdown calculated assuming an impermeable base to the upper aquifer is essentially the same as that of Figure $7 \mathrm{a}$.

In practice, there is often considerable information about aquifer properties but little knowledge of the aquitard beyond its lithology. Based on tabulated ranges for the hydraulic conductivity of materials that comprise unconsolidated aquitards (Freeze and Cherry 1979), 3 to 4 orders of magnitude would be a reasonable uncertainty range for a

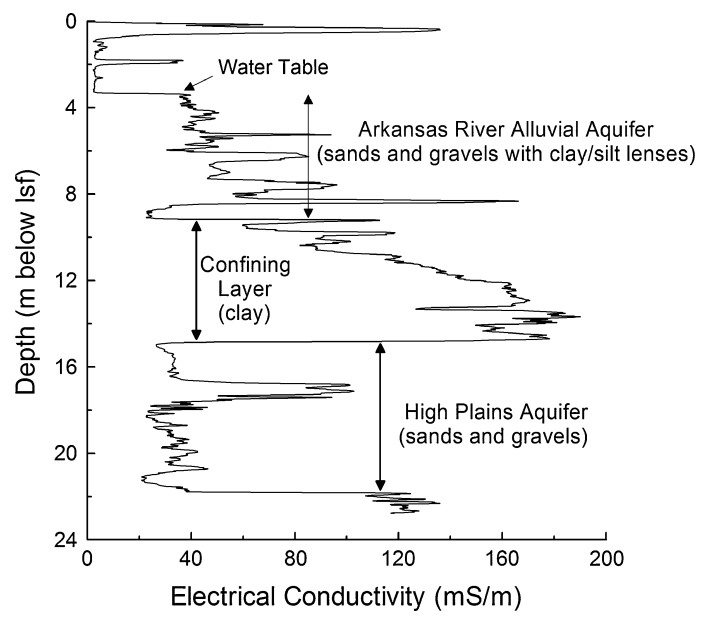

Figure 6. Generalized hydrostratigraphy of the Larned Research Site determined from direct-push electrical conductivity profiling (after Butler et al. 2004).
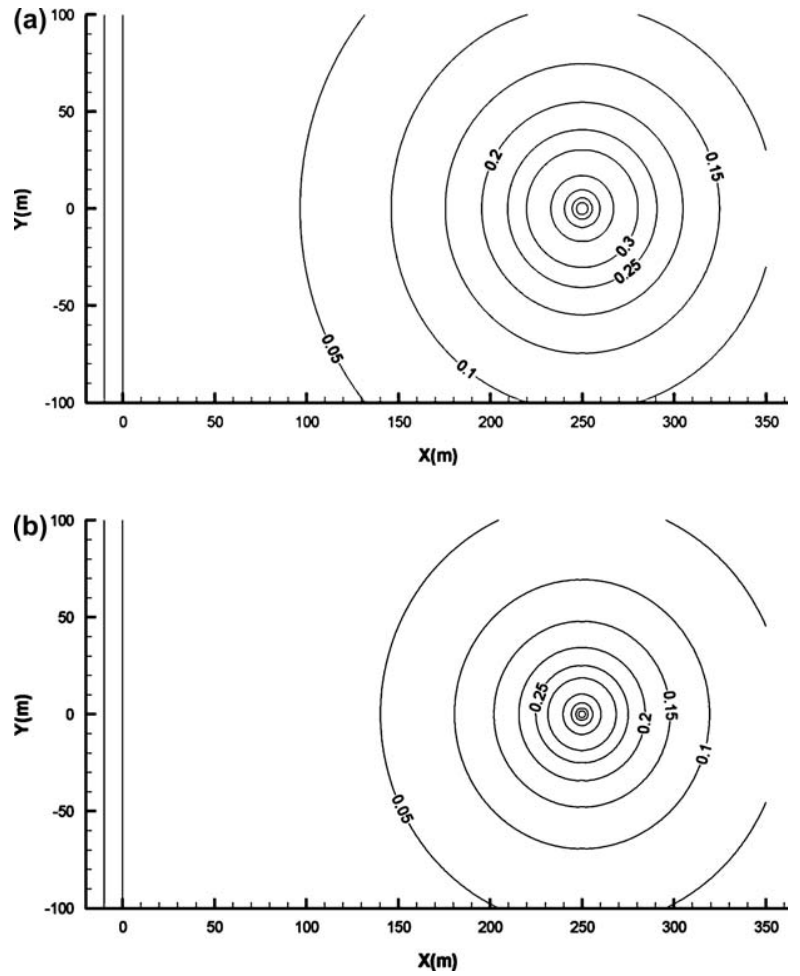

Figure 7. Contour plots of drawdown calculated for a hypothetical pumping well located $250 \mathrm{~m}$ from the river at the Larned Research Site $\left(t=6.05 \times 10^{5} \mathrm{~s}\right.$; river marked by two parallel lines at $x=-10$ and $0 \mathrm{~m}$; contour interval is $0.05 \mathrm{~m}$ [drawdown $<0.30 \mathrm{~m}$ ] and $0.10 \mathrm{~m}$ [drawdown $>0.30 \mathrm{~m}$ ]): (a) parameters of Table 3 and (b) aquitard conductivity 2 orders of magnitude greater than that of Table 3 (note the change in the areal extent of the cone of depression between the two plots).

lithology-based estimate of the hydraulic conductivity of an aquitard. Figure $7 \mathrm{~b}$ illustrates how a 2 order of magnitude increase in aquitard conductivity $\left(k_{\mathrm{c}}=2.4 \times 10^{-6} \mathrm{~m} / \mathrm{s}\right)$ would impact drawdown estimates at the Larned site. As expected, an underprediction in aquitard conductivity results in an overprediction of drawdown.

Similar calculations can be performed for stream depletion at the Larned site. Figure 8 shows the normalized stream depletion rate induced by hypothetical pumping wells located at two distances $(50$ and $250 \mathrm{~m})$ from the river calculated using the parameters of Table 3 . The rate of stream depletion computed assuming an impermeable base to the alluvial aquifer $\left(k_{\mathrm{c}}=0\right)$ is also plotted for reference purposes. The rate during the recovery period is calculated using superposition (Jenkins 1968; Wallace et al. 1990). The area under each of the normalized stream depletion rate curves of Figure 8 is equal to the total volume of stream depletion normalized by the pumping rate; the relative contributions of stream depletion and aquitard leakage to the total volume of pumping-induced recharge can therefore be readily assessed by computing that area. In this case, upward flow through the underlying aquitard appears to be of relatively little importance for pumping wells near the river as aquitard leakage contributes only $7 \%$ of the total volume of recharge for a pumping well located $50 \mathrm{~m}$ from the river (i.e., the volume of stream depletion computed from the 50-m curve of Figure 8 is equal to $93 \%$ of the total volume pumped). 


\begin{tabular}{|ll|}
\hline \multicolumn{2}{|c|}{$\begin{array}{c}\text { Table 3 } \\
\text { Parameter Values for Example }\end{array}$} \\
\hline Parameter & Value \\
\hline Transmissivity ${ }^{1}$ & $4.1 \times 10^{-3} \mathrm{~m}^{2} / \mathrm{s}$ \\
Specific yield ${ }^{1}$ & 0.2 \\
Aquifer thickness ${ }^{1}$ & $4.5 \mathrm{~m}$ \\
Stream width & $10 \mathrm{~m}$ \\
Streambed hydraulic conductivity & $1.2 \times 10^{-5} \mathrm{~m} / \mathrm{s}$ \\
Streambed thickness & $0.3 \mathrm{~m}$ \\
Aquitard hydraulic conductivity ${ }^{1}$ & $2.4 \times 10^{-8} \mathrm{~m} / \mathrm{s}$ \\
Aquitard storage coefficient & $1.0 \times 10^{-5}$ \\
Aquitard thickness ${ }^{1}$ & $5.2 \mathrm{~m}$ \\
Pumping rate & $0.00452 \mathrm{~m}^{3} / \mathrm{s}$ \\
Duration of pumping ${ }^{1}$ & $604,800 \mathrm{~s}$ \\
Distance to the left aquifer boundary & $-\infty$ \\
Distance to the right aquifer boundary & $\infty$ \\
\hline ${ }^{1}$ Parameter values determined from pumping tests described in Butler et al. \\
(2004). Absence of flow in river during these tests prevented estimation of \\
streambed parameters from the drawdown data. Streambed parameters were \\
therefore assigned using physically reasonable values for this setting. \\
\hline
\end{tabular}

However, the relative importance of aquitard leakage increases with distance from the river; leakage contributes $24 \%$ of the total volume of recharge for a pumping well $250 \mathrm{~m}$ from the river. At large distances from the river, aquitard leakage is the major contributor to recharge (65\% of the total volume of recharge for a pumping well located $1000 \mathrm{~m}$ from the river; not included on Figure 8). As shown in this example, stream depletion is not limited to the actual period of pumping. In many cases, the majority, if not all, of the stream depletion may occur in the recovery period (Jenkins 1968; Wallace et al. 1990).

Figure 9 illustrates how uncertainty in aquitard conductivity would impact estimates of the rate of stream

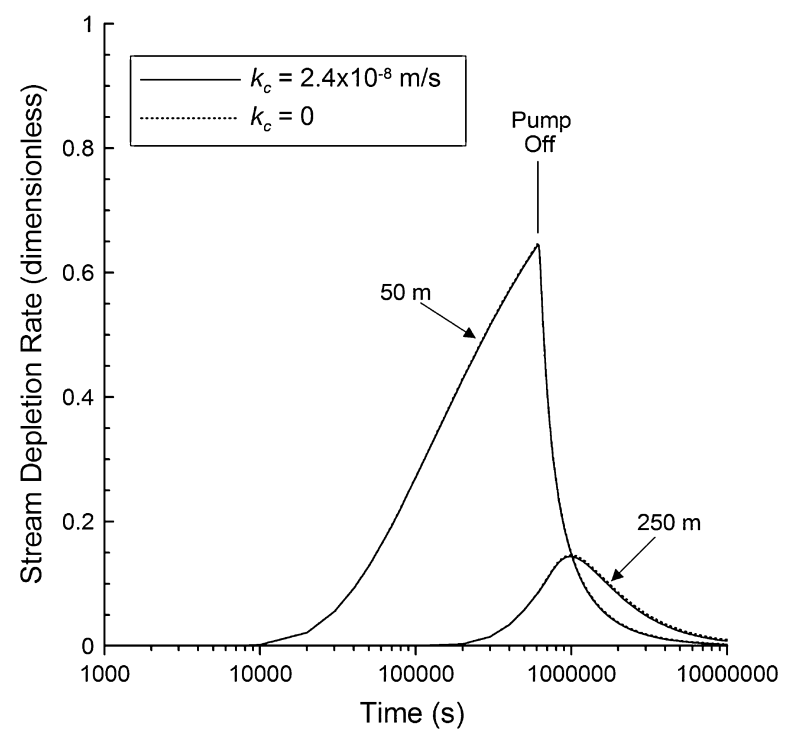

Figure 8. Normalized stream depletion rate vs. time plots for hypothetical pumping wells located 50 and $250 \mathrm{~m}$ from the river at the Larned Research Site $\left(k_{\mathrm{c}}=0\right.$ is for alluvial aquifer with impermeable base; note that plotting format causes apparent differences between curves to be less than actual). depletion at the Larned site. Similar to drawdown, the contribution of aquitard leakage to total recharge is highly dependent on the hydraulic conductivity of the aquitard. If $k_{\mathrm{c}}$ is 1 order of magnitude greater than that of Table 3 $\left(k_{\mathrm{c}}=2.4 \times 10^{-7} \mathrm{~m} / \mathrm{s}\right)$, the aquitard leakage would contribute approximately $21 \%$ and $59 \%$ of the total volume of recharge for pumping wells located 50 and $250 \mathrm{~m}$ from the river, respectively. If $k_{\mathrm{c}}$ is 2 orders of magnitude greater than that of Table $3\left(k_{\mathrm{c}}=2.4 \times 10^{-6} \mathrm{~m} / \mathrm{s}\right)$, the aquitard leakage would contribute $53 \%$ and $94 \%$ of the total volume of recharge for these same wells, respectively. If the pumping well is $1000 \mathrm{~m}$ from the river, leakage contributes almost all of the total volume of recharge for both cases $\left(97 \%\right.$ and $>>99 \%$ for $k_{\mathrm{c}} 1$ and 2 orders of magnitude greater than that of Table 3 , respectively).

The impact of aquitard conductivity lower than that of Table 3 will not be visually apparent in the plotting format of Figure 9. However, that impact cannot be ignored, particularly when the pumping well is located at a relatively large distance from the river. For example, if $k_{\mathrm{c}}$ is an order of magnitude lower than that of Table $3\left(k_{\mathrm{c}}=\right.$ $2.4 \times 10^{-9} \mathrm{~m} / \mathrm{s}$ ), aquitard leakage will contribute $15 \%$ to the total volume of recharge induced by a pumping well located $1000 \mathrm{~m}$ from the river. A 2 order of magnitude smaller $k_{c}\left(2.4 \times 10^{-10} \mathrm{~m} / \mathrm{s}\right)$ will result in a $7 \%$ contribution for this same configuration. In both cases, the contribution of aquitard leakage is vastly different from the $65 \%$ contribution calculated for the parameters of Table 3 .

This hypothetical example demonstrates the impact of aquitard leakage on drawdown and stream depletion in a setting commonly faced in the field. For pumping wells not located in the immediate vicinity of the stream, the potential significance of this impact on stream depletion calculations cannot be overstated. Virtually all of the discharged water may ultimately originate from aquitard leakage and not stream depletion as commonly assumed.

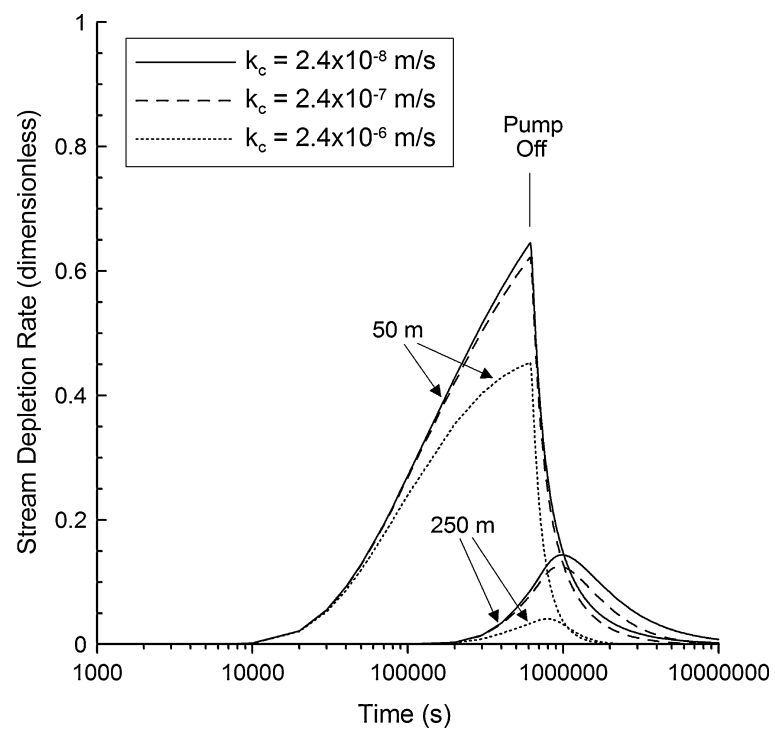

Figure 9. Normalized stream depletion rate vs. time plots as a function of the hydraulic conductivity of the aquitard for hypothetical pumping wells located 50 and $250 \mathrm{~m}$ from the river at the Larned Research Site (solid line same as in Figure 8; note that plotting format causes apparent differences between curves to be less than actual). 
Clearly, failure to consider this mechanism can have serious ramifications for management of water resources in interconnected stream-aquifer systems.

\section{Conclusions}

A new semianalytic solution has been presented for drawdown and stream depletion in an interconnected stream-aquifer system. This solution is based on a model of the stream-aquifer system that is more realistic than that employed in the most commonly used methods for estimation of the impacts of pumping on nearby streams. In particular, following the approach of Hantush (1955, 1964), the base of the aquifer is no longer considered to be an impermeable barrier to flow. Thus, pumpinginduced leakage through an underlying aquitard, a rarely considered but undoubtedly not uncommon recharge mechanism, is incorporated into drawdown and stream depletion calculations. The major findings of this study are described in the following paragraphs.

Aquitard leakage can be an important source of pumping-induced recharge in interconnected stream-aquifer systems. The importance of this recharge mechanism increases as the distance between the pumping well and the stream increases. In contrast to the conditions predicted by the commonly used analytic methods, there will be a distance beyond which drawdown may stabilize but virtually none of the pumping-induced recharge will originate from stream depletion. The distance at which aquitard leakage becomes the dominant recharge mechanism depends on the specifics of the system under consideration. However, even when there is a very large contrast between the hydraulic conductivity of the aquitard and that of the aquifer, aquitard leakage can be the dominant recharge mechanism because of the large surface area over which that leakage occurs.

The ramifications of uncertainty in the estimate of the hydraulic conductivity of the aquitard depend most strongly on the distance between the pumping well and the stream. As this distance increases, the importance of aquitard leakage increases and, therefore, the impact of uncertainty in aquitard conductivity increases. This is in marked contrast to the case of streambed properties, where the relative impact of the uncertainty in streambed properties decreases as the distance between the pumping well and the stream increases (Butler et al. 2001). Thus, knowledge of streambed properties is not required to assess impacts of pumping wells located at large distances from a stream. Ignoring the hydraulic conductivity of the aquitard for those same wells, however, can potentially lead to large errors in assessments of pumping impacts in interconnected stream-leaky aquifer systems.

The preceding findings indicate that considerably more attention should be given to estimating the hydraulic properties of aquitards underlying stream-aquifer systems. Van der Kamp (2001) summarizes the major methods for obtaining hydraulic conductivity estimates in aquitards. Large-scale pumping tests can provide useful estimates of aquitard conductivity, but logistical issues may often limit their use. Slug tests, particularly when configured for use in direct-push equipment (Butler et al.
2002), may be the most convenient means of acquiring information about the hydraulic conductivity of an aquitard for investigations of stream-aquifer systems. However, slug tests only provide information about a limited portion of the aquitard, so the resulting conductivity estimates may not be representative of the bulk average. Clearly, further work is needed on the development of practical methods for obtaining estimates of aquitard conductivity for stream-aquifer assessments.

This work clearly shows that aquitard leakage can potentially be an important recharge mechanism in streamaquifer systems, regardless of the location of the pumping well with respect to the stream. Failure to consider this mechanism can lead to large overestimations of the contribution of stream depletion to the pumping-induced recharge. The ramifications for decisions regarding water resources management and water rights adjudication in interconnected stream-aquifer systems can be significant. The solution presented here provides a convenient tool for assessing the relative contributions of aquitard leakage and stream depletion to the total pumping-induced recharge, thereby shoring up the technical basis of regulatory decisions.

Finally, we should emphasize that this new solution and the insights derived from it must be considered within the light of the major assumptions upon which the solution is based. These assumptions and their ramifications have been discussed in detail by Butler et al. (2001) and Zlotnik (2004). However, two points are worthy of further emphasis. First, as a result of the constant-head condition of Equation 14, the lower aquifer is assumed to be able to provide an unlimited amount of water without significant changes in head. An observation well is therefore needed in the lower aquifer to verify that large head changes, which would greatly diminish the upward flux, are not induced by pumping in the overlying unconfined aquifer. The viability of the constant-head condition may deteriorate as the duration of pumping increases. Batu (1998) summarizes past work on the dependence of this assumption on pumping duration for leaky aquifer systems in the absence of a stream. That previous work should be equally appropriate for the stream-aquifer systems considered here.

Second, prior to invoking aquitard leakage as an important recharge mechanism, one must demonstrate the existence of the assumed pumping-induced head gradient within the aquitard. The solution presented here should not be used for practical assessments of pumping impacts on nearby streams without site-specific data indicating both relatively stable heads in the lower aquifer and a pumping-induced gradient within the aquitard.

\section{Acknowledgments}

This work greatly benefited from reviews provided by Mike Gefell, Hilary Lough, and an anonymous reviewer. In particular, the authors want to gratefully acknowledge Mike Gefell's assistance with the MODFLOW comparisons.

\section{References}

Batu, V. 1998. Aquifer Hydraulics. New York: Wiley. Bear, J. 1979. Hydraulics of Groundwater. New York: McGraw-Hill. 
Butler, J.J. Jr., and M.-S. Tsou. 2003. Pumping-induced leakage in a bounded aquifer: An example of a scale-invariant phenomenon. Water Resources Research 39, no. 12: 1344. doi: 10.1029/2002WR001484.

Butler, J.J. Jr., D.O. Whittemore, X. Zhan, and J.M. Healey. 2004. Analysis of two pumping tests at the O'Rourke Bridge site on the Arkansas River in Pawnee County, Kansas. Kansas Geological Survey Open-File Report 2004-32. Lawrence, Kansas: Kansas Geological Survey.

Butler, J.J. Jr., J.M. Healey, G.W. McCall, E.J. Garnett, and S.P. Loheide II. 2002. Hydraulic tests with direct-push equipment. Ground Water 40, no. 1: 25-36.

Butler, J.J. Jr., V.A. Zlotnik, and M.-S. Tsou. 2001. Drawdown and stream depletion produced by pumping in the vicinity of a partially penetrating stream. Ground Water 39, no. 5: 651-659.

Freeze, R.A., and J.A. Cherry. 1979. Groundwater. Englewood Cliffs, New Jersey: Prentice Hall.

Glover, R.E., and G.G. Balmer. 1954. River depletion resulting from pumping a well near a river. Transactions of the American Geophysical Union 35, no. 3: 468-470.

Hantush, M.S. 1965. Wells near streams with semi-pervious beds. Journal of Geophysical Research 70, no. 12: 2829-2838.

Hantush, M.S. 1964. Hydraulics of wells. In Advances in Hydrosciences, vol. 1, ed. V.T. Chow, 281-432. New York: Academic Press.

Hantush, M.S. 1960. Modification of the theory of leaky aquifers. Journal of Geophysical Research 65, no. 11: 3713-3725.

Hantush, M.S. 1955. Discussion of "River depletion resulting from pumping a well near a river" by Robert E. Glover and Glenn G. Balmer. Transactions of the American Geophysical Union 36, no. 2: 345-346.

Hantush, M.S., and C.E. Jacob. 1955. Non-steady radial flow in an infinite leaky aquifer. Transactions of the American Geophysical Union 36, no. 1: 95-100.

Harbaugh, A.W., and J.M. McDonald. 1996. User's documentation for MODFLOW-96, an update to the U.S. Geological

\section{Appendix 1}

In this section, the transform space form of the solution to the mathematical model defined by Equations 1 through 15 is presented. A general derivation and a description of the approach to invert the transform space expressions are given in Zhan and Butler (2005).

A solution for drawdown can be obtained from Equations 1 through 14 using integral transforms (Robinson 1968). A Laplace transform in time followed by an exponential Fourier transform in the $y$ direction produces FourierLaplace space analogues to Equations 1 through 3. The solution to these equations in Fourier-Laplace space can be written as:

$$
\begin{gathered}
\overline{\bar{s}}_{1}\left(x, \omega_{\mathrm{f}}, p\right)=k_{1}\left[\mathrm{e}^{2 \lambda_{1} x_{\mathrm{lb}}+\lambda_{1} x}+\mathrm{e}^{-\lambda_{1} x}\right] \\
\overline{\bar{s}}_{2}\left(x, \omega_{\mathrm{f}}, p\right)=k_{1}\left[a_{1} \mathrm{e}^{\lambda_{2} x}+b_{1} \mathrm{e}^{-\lambda_{2} x}\right] \\
\overline{\bar{s}}_{3}\left(x, \omega_{\mathrm{f}}, p\right)=k_{1}\left[c_{1} \mathrm{e}^{\lambda_{3} x}+d_{1} \mathrm{e}^{-\lambda_{3} x}\right], 0 \leq x<a \\
\overline{\bar{s}}_{3}\left(x, \omega_{\mathrm{f}}, p\right)=\left(\frac{k_{1} f_{1}}{g_{1}}\right)\left[\mathrm{e}^{\lambda_{3} x}+\mathrm{e}^{2 \lambda_{3} x_{\mathrm{rb}}-\lambda_{3} x}\right], a<x \leq x_{\mathrm{rb}}
\end{gathered}
$$

Survey modular finite-difference ground-water flow model. USGS Open-File Report 96-485. Reston, Virginia: U.S. Geological Society.

Hunt, B. 2003. Unsteady stream depletion when pumping from semiconfined aquifer. Journal of Hydrologic Engineering 8, no. 1: 12-19.

Hunt, B. 1999. Unsteady stream depletion from ground-water pumping. Ground Water 37, no. 1: 98-102.

Jenkins, C.T. 1968. Techniques for computing rate and volume of stream depletion by wells. Ground Water 6, no. 2: 37-46.

Robinson, P.D. 1968. Fourier and Laplace Transforms. New York: Dover.

Schulmeister, M.K., J.J. Butler Jr., J.M. Healey, L. Zheng, D.A. Wysocki, and G.W. McCall. 2003. Direct-push electrical conductivity logging for high-resolution hydrostratigraphic characterization. Ground Water Monitoring and Remediation 23, no. 5: 52-62.

Theis, C.V. 1941. The effect of a well on the flow of a nearby stream. Transactions of the American Geophysical Union 22, no. 3: 734-738.

van der Kamp, G. 2001. Methods for determining the in situ hydraulic conductivity of shallow aquitards-An overview. Hydrogeology Journal 9, no. 1: 5-16.

Wallace, R.B., Y. Darama, and M.D. Annable. 1990. Stream depletion by cyclic pumping of wells. Water Resources Research 26, no. 6: 1263-1270.

Zhan, X., and J.J. Butler Jr. 2005. Mathematical derivations of semianalytical solutions for pumping-induced drawdown and stream depletion in a leaky aquifer system. Kansas Geological Survey Open-File Report 2005-10. Lawrence, Kansas: Kansas Geological Survey. http://www.kgs.ku.edu/ StreamAq.

Zlotnik, V.A. 2004. A concept of maximum stream depletion rate for leaky aquifers in alluvial valleys. Water Resources Research 40, W06507. doi:10.1029./2003WR002932 where $\overline{\bar{s}}_{i}$ is the Fourier-Laplace transform of $s_{i}$; $p$ is the Laplace transform variable; $\omega_{\mathrm{f}}$ is the Fourier transform variable; $\lambda_{1}=\left(\omega_{\mathrm{f}}^{2}+\Gamma_{1}+P_{1} p\right)^{1 / 2}$; $\lambda_{2}=\left(\omega_{\mathrm{f}}^{2}+\Gamma_{2}+\mathrm{L}+P_{2} p\right)^{1 / 2} ; \quad \lambda_{3}=\left(\omega_{\mathrm{f}}^{2}+\Gamma_{3}+P_{3} p\right)^{1 / 2} ;$ $P_{i}=S_{i} / T_{i} ; \quad \mathrm{L}=k^{\prime} /\left(b^{\prime} T_{2}\right) ; \quad \Gamma_{i}=\left(k_{\mathrm{c}} S_{\mathrm{Sc}} p\right)^{1 / 2} / T_{i} ;$ $a_{1}=\frac{1}{2}\left(\mathrm{e}^{2 \lambda_{1} x_{\mathrm{lb}}-\lambda_{1} w+\lambda_{2} w}+\mathrm{e}^{\left(\lambda_{1}+\lambda_{2}\right) w}\right)+\frac{\lambda_{1}}{2 \gamma_{1} \lambda_{2}}\left(\mathrm{e}^{2 \lambda_{1} x_{\mathrm{lb}}-\lambda_{1} w+\lambda_{2} w}\right.$

$$
\left.-\mathrm{e}^{\left(\lambda_{1}+\lambda_{2}\right) w}\right) ; \quad b_{1}=\frac{1}{2}\left(\mathrm{e}^{2 \lambda_{1} x_{\mathrm{lb}}-\lambda_{1} w-\lambda_{2} w}+\mathrm{e}^{\left(\lambda_{1}-\lambda_{2}\right) w}\right)
$$$$
-\frac{\lambda_{1}}{2 \gamma_{1} \lambda_{2}}\left(\mathrm{e}^{2 \lambda_{1} x_{\mathrm{lb}}-\lambda_{1} w-\lambda_{2} w}-\mathrm{e}^{\left(\lambda_{1}-\lambda_{2}\right) w}\right) ;
$$

$c_{1}=\frac{1}{2}\left[a_{1}+b_{1}\right]+\frac{\lambda_{2}}{2 \gamma_{2} \lambda_{3}}\left[a_{1}-b_{1}\right]$;

$d_{1}=\frac{1}{2}\left[a_{1}+b_{1}\right]-\frac{\lambda_{2}}{2 \gamma_{2} \lambda_{3}}\left[a_{1}-b_{1}\right]$;

$e_{1}=-Q /\left(T_{3} \lambda_{3} p \sqrt{2 \pi}\right)$

$f_{1}=c_{1} \mathrm{e}^{\lambda_{3} a}+d_{1} \mathrm{e}^{-\lambda_{3} a}$

$g_{1}=\mathrm{e}^{\lambda_{3} a}+\mathrm{e}^{2 \lambda_{3} x_{\mathrm{rb}}-\lambda_{3} a} ; \quad h_{1}=c_{1} \mathrm{e}^{\lambda_{3} a}-d_{1} e^{-\lambda_{3} a} ;$

$j_{1}=\mathrm{e}^{\lambda_{3} a}-\mathrm{e}^{2 \lambda_{3} x_{\mathrm{rb}}-\lambda_{3} a} ; k_{1}=e_{1} g_{1} /\left[f_{1} j_{1}-h_{1} g_{1}\right] ; \gamma_{1}=T_{2} / T_{1} ;$ and $\gamma_{2}=T_{3} / T_{2}$.

The Laplace-space expression for the rate of stream depletion in a laterally bounded leaky aquifer is:

$$
\overline{\Delta q}(p)=\frac{k_{1}}{\lambda_{2}^{*}}\left[a_{1}\left(1-\mathrm{e}^{-\lambda_{2}^{*} w}\right)-b_{1}\left(1-\mathrm{e}^{\lambda_{2}^{*} w}\right)\right]
$$

where $\overline{\Delta q}$ is the Laplace transform of $\Delta q$ and $\lambda_{2}^{*}=\left(\Gamma_{2}+\mathrm{L}+P_{2} p\right)^{1 / 2}$. 